\title{
Protective Effects of Hydrogen Sulfide Against Cigarette Smoke Exposure-Induced Placental Oxidative Damage by Alleviating Redox Imbalance via Nrf2 Pathway in Rats
}

\author{
Fusheng Zhao a, b Fang Leia Xiang Yan ${ }^{\mathrm{a}} \quad$ Senfeng Zhang ${ }^{\mathrm{a}} \quad$ Wen Wang ${ }^{\mathrm{a}}$ \\ Yu Zhenga \\ aDepartment of Physiology, West China School of Basic Medical Sciences and Forensic Medicine, \\ Sichuan University, Chengdu, Sichuan, ${ }^{\mathrm{D} D e p a r t m e n t}$ of Physiology, Mudanjiang Medical University, \\ Mudanjiang, Heilongjiang, China
}

\section{Key Words}

Hydrogen sulfide - Nuclear factor erythroid 2-related factor 2 - Oxidative stress - Placental damage $\cdot$ Redox imbalance

\begin{abstract}
Background/Aims: Cigarette smoke exposure (CSE) during pregnancy is a well-recognized health hazard that causes placental damage. Hydrogen sulfide $\left(\mathrm{H}_{2} \mathrm{~S}\right)$ has been reported to protect multiple organs from injury. However, the protective effects of $\mathrm{H}_{2} \mathrm{~S}$ have not been tested in the placenta. This study aimed to explore the potential of $\mathrm{H}_{2} \mathrm{~S}$ in protecting placenta against oxidative injury induced by CSE during pregnancy and the possible underlying mechanisms. Methods: Pregnant SD rats were randomly divided into 4 groups: $\mathrm{NaCl}, \mathrm{NaHS}(\mathrm{a}$ donor of $\left.\mathrm{H}_{2} \mathrm{~S}\right), \mathrm{CSE}$ and $\mathrm{CSE}+\mathrm{NaHS}$. Placental oxidative damage was detected by 8-hydroxy2-deoxyguanosine (8-OHdG) stain and malondialdehyde (MDA) assay. Placental redox status was assessed by measuring reactive oxygen species (ROS), total antioxidant capacity (T-AOC) and glutathione (GSH) levels, as well as copper/zinc SOD (SOD1), manganese SOD (SOD2), catalase (CAT) and glutathione peroxidase (GPx) activities and expressions. Meanwhile, nuclear factor erythroid 2-related factor 2 (Nrf2) was analyzed by immunohistochemistry, real-time PCR and Western blot. Results: We found that NaHS markedly reduced the elevated levels of 8-OHdG and MDA induced by CSE. Further, NaHS treatment effectively mitigated CSE-induced placental redox imbalance by inhibiting ROS production, restoring T-AOC level, increasing GSH/GSSG ratio, and augmenting SOD1 SOD2, CAT and GPx activities and expressions. More notably, NaHS administration also reversed the aberrant decrease of Nrf2 due to CSE in rat placentas. Conclusion: Our data demonstrate that $\mathrm{H}_{2} \mathrm{~S}$ can protect against CSE-induced placental oxidative damage probably by alleviating redox imbalance via Nrf2 pathway.




\section{Introduction}

Cigarette smoke is one of the major environmental health risk factors affecting almost all the organs or systems of human body [1-4]. A growing body of evidence indicates that maternal smoking or cigarette smoke exposure (CSE) during pregnancy is associated with a variety of placental complications, including alterations to the development and function of the placenta $[5,6]$. Histologically, the placentas from smokers display changes including the thickened trophoblastic basement membrane, increased collagen in the villous stroma [7, 8], and degenerated organelles in syncytiotrophoblasts [9]. Functionally, these modifications appear to alter placental blood flow [10], and disturb progesterone production [11], estrogen metabolism [12], amino acid transport [13], as well as the activity of drug-metabolizing enzymes [14]. It is worth noting that CSE during pregnancy is also associated with increased risks of placenta-associated syndromes [15], such as preterm birth, placenta previa and placental abruption $[16,17]$.

Cigarette smoke is a highly complex mixture containing nearly 4500 chemical constituents, including nicotine, carbon monoxide, toxic metals, and a substantial amount of reactive oxygen species (ROS) $[6,18]$. Moreover, cigarette smoke also triggers ROS formation in a variety of cells [19]. A vast array of evidence indicates that excessive ROS production, exceeding the anti-oxidative capacity of cells, may damage cell components such as DNA, protein, and lipids, and then cause cellular dysfunction [20]. Meanwhile, a number of adverse events associated with oxidative stress are observed in tissues following CSE, which include cardiac hypertrophy [21], pulmonary fibrosis [22] as well as endothelial cells injury [23]. In mammalian cells, ROS is scavenged by a host of enzymatic antioxidants including superoxide dismutase (SOD), catlase (CAT) and glutathione peroxidase (GPx), and nonenzymatic antioxidants, such as glutathione (GSH) [20,24]. Nuclear factor erythroid 2-related factor 2 (Nrf2) is a redox-sensitive transcription factor that regulates the transcriptional activation of anti-oxidative genes [25]. Under physiological conditions, Nrf2 is bound to its natural inhibitor Kelch-like-ECH-associated protein 1 (Keap1) in the cytoplasm [25]. In the presence of oxidative or xenobiotic stimuli, Nrf2 dissociates from Keap1 and translocates into the nucleus, where it binds to the antioxidant response element, and initiates the transcription of anti-oxidative genes encoding the respective proteins such as SOD, CAT, GPx and heme oxygenase-1 [26]. Deficiency of Nrf2 was shown to exacerbate cerebral infarction and neurologic deficits in animal models $[27,28]$. Further, studies displayed that Nrf2 disruption made mice highly susceptible to CSE-induced emphysema [29, 30]. By contrast, activation of Nrf2 could alleviate lung oxidative stress response, alveolar destruction, alveolar cells apoptosis, and pulmonary hypertension imposed by chronic CSE in mice [31]. In addition, growing evidence suggests that Nrf2 has protective effects in various organs and tissues, including the brain [32], heart [33] and liver [34]. Nevertheless, to date, no previous studies have investigated whether Nrf2 can protect the placenta against CSE-induced oxidative damage.

Hydrogen sulfide $\left(\mathrm{H}_{2} \mathrm{~S}\right)$, which can be synthesized by cystathionine- $\beta$-synthase (CBS), cystathionine- $\gamma$-lyase (CGL) and 3-mercaptopyruvate sulfurtransferase (3-MST) in mammal cells, has been considered as the third endogenous gaseous signaling molecule, along with nitric oxide and carbon monoxide, to regulate a variety of physiological and pathological processes in organs $[35,36]$. Animal models and human studies have identified that $\mathrm{H}_{2} \mathrm{~S}$ possess potent anti-oxidative activity and other physiological functions. For instance, $\mathrm{H}_{2}^{2} \mathrm{~S}$ plays an important role in regulating the response to ischemia/reperfusion injuries in heart [37], liver [38] and brain [39]. A previous study showed that inhalation of $\mathrm{H}_{2} \mathrm{~S}$ could alleviate cotton smoke-induced lung injury by reducing the production of inducible nitric oxide synthase and nitric oxide in rats [40]. In addition, an in vivo study revealed that $\mathrm{H}_{2} \mathrm{~S}$ could improve cigarette smoking-induced left ventricular systolic dysfunction via inhibition of apoptosis and autophagy in rats [41]. In our previous works, we found that $\mathrm{H}_{2} \mathrm{~S}$ could alleviate medullary respiratory centers injury induced by in utero CSE in neonatal rats [42], 
and that $\mathrm{H}_{2} \mathrm{~S}$ could also protect against acute hypoxia-induced medullary respiratory centers impairment via anti-oxidant and anti-apoptotic effects in adult rats [43]. However, whether $\mathrm{H}_{2} \mathrm{~S}$ can protect the placenta against CSE-induced oxidative injury is still unclear.

Given the anti-oxidative activity of $\mathrm{H}_{2} \mathrm{~S}$ and the critical role of Nrf2 in cellular redox pathways, we aimed therefore in the present study to explore whether $\mathrm{H}_{2} \mathrm{~S}$ can protect against CSE-induced placental oxidative damage in rats, and to clarify whether the Nrf2 pathway is involved in the protection.

\section{Materials and Methods}

\section{Animal grouping}

Adult Sprague-Dawley rats (body weight: female, 240-260 g; male, 360-380 g) were obtained from Sichuan University Experimental Animal Center. The rats were housed in groups in a room with a light/ dark cycle of $12 \mathrm{~h} / 12 \mathrm{~h}$ at $22 \pm 1^{\circ} \mathrm{C}$ and were provided with access to standard pellet diet and water ad libitum. Animals were acclimatized to the environment for 7 days prior to the experiments. Pregnancies were established by mating nulliparous female rats with fertile male rats at a ratio of 2:1 overnight. Pregnancy was confirmed by the presence of spermatozoa on the vaginal smear and the day was considered as gestational day (gd) 0 . Pregnant rats were randomly divided into 4 groups: $\mathrm{NaCl}$, $\mathrm{NaHS}$ (donor of $\mathrm{H}_{2} \mathrm{~S}$ ), CSE and CSE+NaHS. All animal experiments were carried out in strict accordance with the recommendation in the National Institute of Health Guide for the Care and Use of Laboratory Animals (NIH publications No. 8023) revised 1978, and approved by the Animal Care and Use Committee of Sichuan University.

\section{Maternal cigarette smoke exposure}

Maternal CSE was performed as previously published [42, 44]. Briefly, pregnant rats were placed in a restraining exposure box $(80 \mathrm{~cm} \times 60 \mathrm{~cm} \times 50 \mathrm{~cm})$ with cigarette smoke delivered cyclically $(2$ cigarette $/ 12$ min, 10 min with the box closed and the remaining 2 min with the box open, repeated five times) by lighting cigarettes (Tianxiaxiu, $11 \mathrm{mg}$ of tar and $1 \mathrm{mg}$ of nicotine per cigarette, China Tobacco Chuanyu Industrial Co., China). CSE was conducted twice a day (starting at 9:00 a.m. and 16:00 p.m., respectively) during gd 7-20.

In addition to the CSE treatment as described above, the pregnant rats in CSE and CSE+NaHS groups received an equivalent volume of physiological saline and $\mathrm{NaHS}(56 \mu \mathrm{mol} / \mathrm{kg})$, respectively, intraperitoneally administered at $2.5 \mathrm{ml} / \mathrm{kg}$ body weight $30 \mathrm{~min}$ before the first smoke exposure each day. Previous studies in our laboratory have determined the serum cotinine level by means of ELISA. Using this regimen, the serum cotinine concentration $(92.3 \pm 15.7 \mathrm{ng} / \mathrm{ml})$ [42] achieves a level of smoke exposure that simulates active smoking during pregnancy $[45,46]$. The pregnant rats in $\mathrm{NaCl}$ and $\mathrm{NaHS}$ groups were exposed to air under a similar condition and were intraperitoneally injected with an equivalent volume of physiological saline and NaHS $(56 \mu \mathrm{mol} / \mathrm{kg})$, respectively.

On gd 21 , the pregnant rats from all groups were anesthetized with $10 \%$ chloral hydrate $(3 \mathrm{ml} / \mathrm{kg}$ ) via intraperitoneal injection and cesarean sections were performed to harvest the placentas, and the fetuses were euthanized by decapitation after ether inhalation. Placentas from the litters with $10 \sim 12$ fetuses were collected (8 litters each group). The placentas were carefully dissected from the maternal mesometrial triangle and umbilical cords, cleaned amniotic fluid as well as blood. Then, the placentas were immediately fixed in $4 \%$ paraformaldehyde for immunohistological staining, or placed in RNALater for real-time PCR, or frozen in liquid nitrogen for Western blot and biochemical analysis.

\section{Immunohistological staining}

One placenta was randomly chosen from each litter and fixed in 4\% paraformaldehyde overnight at $4^{\circ} \mathrm{C}$, then the placentas were bisected and oriented during the paraffin embedding procedure so that the cut face exhibited a transverse view of the placenta. Serial sections were cut at an interval of $50 \mu \mathrm{m}$, and total three intervals were made, then the sections $(5 \mu \mathrm{m})$ were deparaffinized, rehydrated and rinsed in distilled water. Endogenous peroxidase activity was blocked by a 30 min incubation in $3 \% \mathrm{H}_{2} \mathrm{O}_{2}$ at room temperature, then antigens were retrieved by heating in $0.01 \mathrm{M}$ sodium citrate (pH 6.0) for $20 \mathrm{~min}$. After three washes in phosphate buffered saline (PBS), the sections were blocked with $3 \%$ normal goat serum (Chemicon International Inc., Temecula, CA, USA) for $60 \mathrm{~min}$ in room temperature. The sections were 


\section{Cellular Physiology Cell Physiol Biochem 2018;48:1815-1828 \begin{tabular}{ll|l} 
and Biochemistry Published onlıne: August 8, 2018 & $\begin{array}{l}\text { (c) } 2018 \text { The Author(s). Published by S. Karger AG, Basel } \\
\text { www.karger.com/cpb }\end{array}$
\end{tabular}

incubated at $4^{\circ} \mathrm{C}$ overnight with rabbit anti-8-OHdG (1:200; Proteintech, Chicago, IL, USA) and Nrf2 (1:250; Proteintech, Chicago, IL, USA), respectively, in PBS containing 1\% goat serum. After washed in PBS, sections were incubated for $60 \mathrm{~min}$ at room temperature with goat anti-rabbit IgG peroxidase-polymer secondary antibody (Proteintech, Chicago, IL, USA). The signals were developed with acetate-imidazol buffer containing $2.5 \%$ nickel sulfate and $0.05 \%$ 3, 3'-diaminobenzidine tetrahydrochochloride (DAB; Sigma-Aldrich, St. Louis, MO, USA) for $5 \mathrm{~min}$, then the sections were counterstained with hematoxylin. Finally, the sections were dehydrated through graded ethanol series, cleared in xylene, and covered with Cytoseal (Stephens Scientific, Kalamazoo, MI, USA). For the negative reagent control, the primary antibody was omitted. The sections were processed at the same time using the same chemical reagents to avoid batch-to-batch variation during immunostaining.

To analyze the expressions of $8-\mathrm{OHdG}$ and Nrf2 in placentas, the labyrinthine zones were chosen to photograph using a microscope (Olympus BX51T, Olympus Corp., Tokyo, Japan). As previous study described [47], the immunoreactivity intensity was quantified with Image Pro-Plus 6.0 software (Media Cybernetics, Bethesda, MD, USA) by an operator blind to the placental groups. Values of optical density (OD) were calculated by the equation: $\sum$ integral optical density/ $/$ area, where integral optical density is the integral optical density in a region of interest, and area is the area of a region of interest. In this study, Sintegral optical density is the sum of integral optical density of all cells in the photograph and $\sum$ area is the total area of all cells in the photograph.

\section{Lipid peroxidation evaluation}

The level of MDA was evaluated using an assay kit (Nanjing Jiancheng Bioengineering Institute, Nanjing, Jiangsu, China) as previous study described [48]. Briefly, the placental tissues were homogenized independently in ice-cold saline (1:10, wt/vol), and incubated with thiobarbituric acid at $95^{\circ} \mathrm{C}$ for 40 min, then the reaction mixtures were cooled to room temperature and centrifuged at $3500 \mathrm{rpm}$ for 10 min. The supernatants were collected and measured spectrophotometrically at $532 \mathrm{~nm}$ according to the manufacturer's instructions. Each measurement was performed in duplicate. Samples were normalized for differences in the amount of protein as determined by a DC protein concentration assay (Bio-Rad, Hercules, CA, USA).

\section{Fluorescent staining}

The level of ROS in placenta was detected using CellROX ${ }^{\circledR}$ Deep Red Reagent (Life Techologies, Carlsbad, CA, USA) as previous study described [49]. In brief, the frozen placentas were cut at an interval of $50 \mu \mathrm{m}$, and total three intervals were made, then the sections $(12 \mu \mathrm{m})$ were washed in PBS, and incubated with CellROX ${ }^{\circledR}$ Deep Red $(5 \mu \mathrm{M})$ in PBS for $30 \mathrm{~min}$ at $37^{\circ} \mathrm{C}$ in a humidified chamber protected from light. The placental labyrinthine zone was chosen for imaging at an excitation wavelength of $633 \mathrm{~nm}$ (emission range of 640-680 nm) with a fluorescence microscope (Olympus BX51TR, Olympus Corp., Tokyo, Japan). Three visual fields were randomly photographed with a $40 \times$ objective, and the camera parameters were kept constant during imaging. For quantitative analysis of the ROS, integral fluorescence density of the region of interest was measured with Image-Pro Plus 6.0 software (Media Cybernetics, Bethesda, MD, USA) by an operator blind to the placental groups, as previous study described [47].

\section{Total antioxidant activity assessment}

The level of T-AOC was measured using an assay kit (Nanjing Jiancheng Bioengineering Institute, Nanjing, Jiangsu, China). Briefly, placental tissues were homogenized independently in ice-cold saline (1:10, wt/vol), and the homogenate was fully blend and kept still for $10 \mathrm{~min}$, then the supernatant was centrifuged at $1000 \mathrm{~g}$ at $4^{\circ} \mathrm{C}$, and the pellet was discarded and the supernatant was collected and measured spectrophotometrically at $520 \mathrm{~nm}$ according to the manufacture's instructions.

\section{Glutathione measurement}

Total GSH and GSSG in placental homogenates were measured using a GSH/GSSH assay kit (Nanjing Jiancheng Bioengineering Institute, Nanjing, Jiangsu, China) according to the manufacturer's instructions. Reduced GSH was calculated as a difference between total GSH and GSSG, and the GSH/GSSG ratio was determined. The protein concentration for each sample was determined by a DC protein concentration assay (Bio-Rad, Hercules, CA, USA). 


\section{Cellular Physiology Cell Physiol Biochem 2018;48:1815-1828 \begin{tabular}{ll|l} 
and Biochemistry Published online: August 8, 2018 & $\begin{array}{l}\text { (c) } 2018 \text { The Author(s). Published by S. Karger AG, Basel } \\
\text { www.karger.com/cpb }\end{array}$
\end{tabular}}

\section{Antioxidant enzyme activities assay}

The enzymatic activities of SOD1, SOD2, CAT and total GPx in placental homogenates were assessed, respectively, using commercially available kits (Nanjing Jiancheng Bioengineering Institute, Nanjing, Jiangsu, China). Briefly, the placentas were homogenized independently and centrifuged at $3500 \mathrm{rpm}$ for $10 \mathrm{~min}$ at $4{ }^{\circ} \mathrm{C}$, the supernatants were incubated, respectively, with total SOD, SOD1, CAT and GPx reaction solutions, and then measured spectrophotometrically at $550 \mathrm{~nm}$ (total SOD and SOD1), $240 \mathrm{~nm}$ (CAT) and $340 \mathrm{~nm}$ (total GPx), respectively, according to the manufacture's instructions. The activity of SOD2 was calculated as a difference between total SOD and SOD1.

\section{Quantitative real-time PCR analysis}

The quantitative real-time PCR analysis was performed as previous study described [50]. Briefly, total RNA was extracted from placental tissues using TRIzol reagent (Invitrogen Life Technologies, Carlsbad, CA, USA) according to the manufacturer's instructions, and the RNA concentration was quantified by a spectrophotometer (NanoDrop 2000, Thermo Scientific, Waltham, MA, USA). Reverse transcription of an equal amount of total RNA was performed using a Thermo Scientific Revert Aid First Strand cDNA kit (Thermo Scientific, Waltham, MA, USA). The primer pairs for Sod1, Sod2, Cat, GPx1 and Nrf2 were shown in Table 1. Quantitative real-time PCR was performed with SsoFast EvaGreen ${ }^{\circledR}$ Supermix (BioRad Laboratories, Hercules, CA, USA) using CFX96 Touch ${ }^{\mathrm{TM}}$ Real-Time PCR Detection System ( Bio-Rad Laboratories, Inc., Hercules, CA, USA) with $0.5 \mu \mathrm{g}$ of cDNA. $\beta$-actin was used as the reference gene. Samples were run in triplicate to ensure amplification integrity. The final volume of the PCR reaction mixture was 20 $\mu \mathrm{l}$, which consisted of $10 \mu \mathrm{l} 2 \times$ SYBR supermix, $0.5 \mu \mathrm{l} 10 \mu \mathrm{M}$ forward primer and reverse primer, $1 \mu \mathrm{l}$ cDNA, and $8 \mu \mathrm{l}$ Rnase/DNase-free water. The PCR cycling conditions were as follows: $95^{\circ} \mathrm{C}$ for $30 \mathrm{sec}$, followed by 40 cycles of $95^{\circ} \mathrm{C}$ for $5 \mathrm{sec}$ and $60^{\circ} \mathrm{C}$ for $5 \mathrm{sec}$. Data were collected during each cycle at the $60^{\circ} \mathrm{C}$ extension step. The amplification efficiency was tested in standard curves using serial cDNA dilutions. Amplification specificity was checked using melting curves. The quantitation values of target genes were normalized to the endogenous $\beta$-actin control gene. The relative fold changes in gene expression levels were obtained by comparing the $2^{-\Delta \Delta \mathrm{Ct}}$ data of the different groups.

\section{Western blot analysis}

The Western blot analysis was performed as previous study described [51]. Briefly, the placental tissue was homogenized independently in RIPA buffer (Beyotime, Nanjing, Jiangsu, China) with 1\% phenylmethylsulfonyl fluoride (Beyotime, Nanjing, Jiangsu, China) and protease inhibitor (Sigma Aldrich, St Louis, MO, USA) according to the manufacturer's instructions at $4^{\circ} \mathrm{C}$. After centrifugation at $12,000 \mathrm{rpm}$ for $10 \mathrm{~min}$, the supernatant was collected and quantified by BCA (bicinchoninic acid) Protein Assay Kit (Beyotime, Nanjing, Jiangsu, China) and stored at $-80^{\circ} \mathrm{C}$. An equal amount of total protein $(30 \mathrm{mg}) \mathrm{was}$ loaded and separated by SDS-PAGE and transferred to PVDF membranes (Millipore, Billerica, MA, USA). The membranes were blocked with 5\% non-fat milk in TBS-T $(10 \mathrm{mmol} / \mathrm{L}$ Tris, $150 \mathrm{mmol} / \mathrm{L} \mathrm{NaCl}$ and $0.1 \%$ Tween 20, pH7.5) for $2 \mathrm{~h}$ at room temperature, and then incubated with diluted primary antibodies: rabbit SOD1 (1:800), SOD2 (1:800), CAT (1:600), GPx1 (1:600), Nrf2 (1:400) and $\beta$-actin (1:2000) (Proteintech,

Table 1. Primers sequences for the real time quantitive PCR

\begin{tabular}{|c|c|c|c|}
\hline Gene & NCBI accession No. & Primer sequences ( $\left.5^{\prime}-3^{\prime}\right)$ & Product size (bp) \\
\hline Sod1 & NM_017050.1 & For: AATGTGTCCATTGAAGATCGTGTGA & 127 \\
\hline Sod2 & NM_017051.2 & $\begin{array}{l}\text { Rev: ATGTTTCTGACCTTTACGACCTTCG } \\
\text { For: GACCCAAAGTCACGCTTGATA } \\
\text { Rev: ATCCCGAGTCCAAACAGGTC }\end{array}$ & 102 \\
\hline Cat & NM_012520.2 & $\begin{array}{l}\text { For: AGCCAGAAGAGAAACCCACA } \\
\text { Rev: TGAAAGAACAAGTCGCTGGC }\end{array}$ & 104 \\
\hline GPx1 & NM_030826.4 & $\begin{array}{l}\text { For: ATGCCTTAGGGGTTGCTAGG } \\
\text { Rev: AGATATAGCCCAAGCTACAGC }\end{array}$ & 129 \\
\hline Nrf2 & NM_031789.2 & $\begin{array}{l}\text { For: GAGACGGCCATGACTGAT } \\
\text { Rev: AATGAGTAGCTAGGGGAGTG }\end{array}$ & 120 \\
\hline$\beta$-actin & NM_031144.3 & $\begin{array}{l}\text { For: GGTGAAGGTCGGAGTCAACG } \\
\text { Rev: CCAGTAGGTACTGTTGAAAC }\end{array}$ & 112 \\
\hline
\end{tabular}




\section{Cellular Physiology Cell Physiol Biochem 2018;48:1815-1828 \begin{tabular}{ll|l} 
DOI: 10.1159/000492504 & and Biochemistry 2018 The Author(s). Published by S. Karger AG, Basel \\
Published onlne: August 8, 2018 & $\begin{array}{l}\text { www.karger.com/cpb } \\
\text { and }\end{array}$
\end{tabular} \\ Zhao et al.: Hydrogen Sulfide and Placental Oxidative Damage}

Chicago, IL, USA) at $4^{\circ} \mathrm{C}$ overnight. On the following day, the membranes were washed in TBS-T and incubated with the appropriate secondary antibodies conjugated to horseradish peroxidase for $2 \mathrm{~h}$ at room temperature. The target protein bands were visualized with chemiluminescence luminol reagents (ECL; millipore, Billerica, MA, USA). Blots were imaged by Molecular Image ${ }^{\circledR} \mathrm{ChemiDoc}^{\mathrm{TM}} \mathrm{XRS}^{+}$with Image Lab $^{\text {TM }}$ Software (Bio-Rad, Hercules, CA, USA). The tests were performed three times and quantification was analyzed by Image J 1.50 b Gel Analyzer (National Institutes of Health, Washington, DC, USA). Western blot data were normalized relative to the density of the $\beta$-actin bands.

\section{Statistical analysis}

All data were presented as mean \pm standard error. Statistical analysis of all the data was done using two-way ANOVA with SPSS software (version 17.0). Statistical significance was set at $P<0.05$.

\section{Results}

NaHS alleviates placental oxidative damage induced by CSE

To investigate the effects of CSE and $\mathrm{H}_{2} \mathrm{~S}$ on placental oxidative damage, we detected the level of 8-hydroxy-2deoxyguanosine (8-OHdG), a marker for DNA oxidative damage, in placentas. Results showed that the immunoreactivity of 8-OHdG was scarce and sparsely distributed in placentas of the $\mathrm{NaCl}$ and NaHS groups (Fig. 1A and B). By contrast, abundant 8-OHdG immunoreactivity was observed in the placentas of the CSE group (Fig. 1C), whereas the increased 8-OHdG immunoreactivity was reduced with NaHS treatment in the CSE+NaHS group (Fig. 1D). Quantitative analysis (Fig. 1E) revealed that the mean level of $8-0 \mathrm{HdG}$ in the CSE group was significantly higher than that in the $\mathrm{NaCl}$ group $(P<0.05)$, whereas the increased 8-OHdG due to CSE was decreased with NaHS treatment in the CSE+NaHS group $(P<0.05)$. There was no significant difference between NaHS and $\mathrm{NaCl}$ groups in terms of $8-\mathrm{OHdG}$ levels $(P>0.05)$.

To test the effects of $\mathrm{CSE}$ and $\mathrm{H}_{2} \mathrm{~S}$ on placental oxidative damage, we also measured the content of malondialdehyde (MDA), a marker for lipid peroxidation, in placentas. As displayed in Fig. 2, The

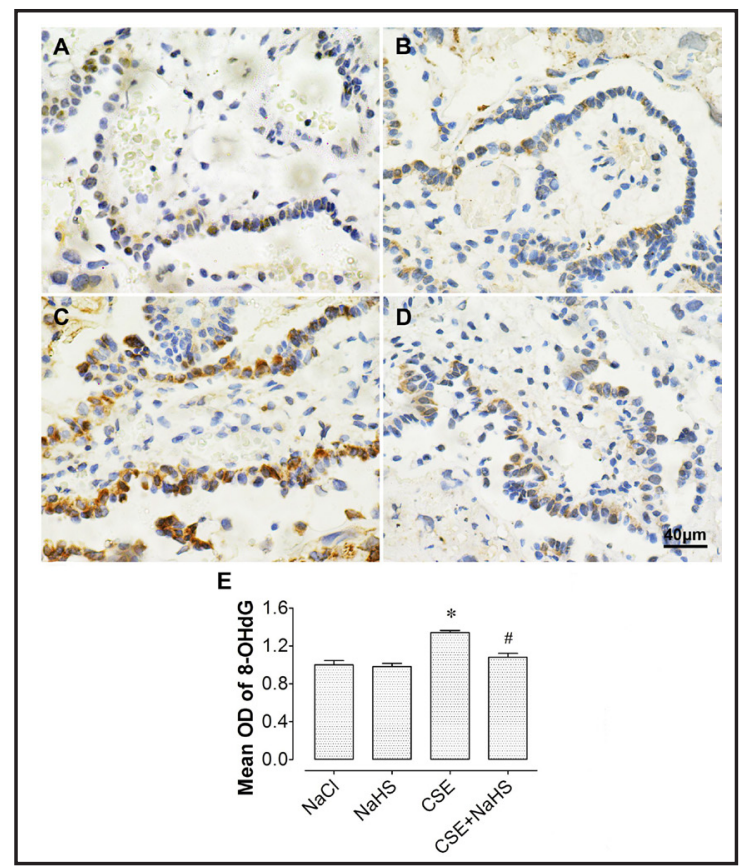

Fig. 1. NaHS alleviates CSE-induced DNA oxidative damage in placentas. (A-D) Representative images for 8-OHdG immunostaining of placentas in the $\mathrm{NaCl}$, NaHS, CSE and CSE+NaHS groups, respectively. (E) Comparisons of optical density (OD) values of 8-OHdG in the $\mathrm{NaCl}, \mathrm{NaHS}, \mathrm{CSE}$ and $\mathrm{CSE}+\mathrm{NaHS}$ groups. ${ }^{*} \mathrm{P}<0.05$ vs. $\mathrm{NaCl}$ group; $\# \mathrm{P}<0.05$ vs. CSE group. $\mathrm{n}=6$ per group.

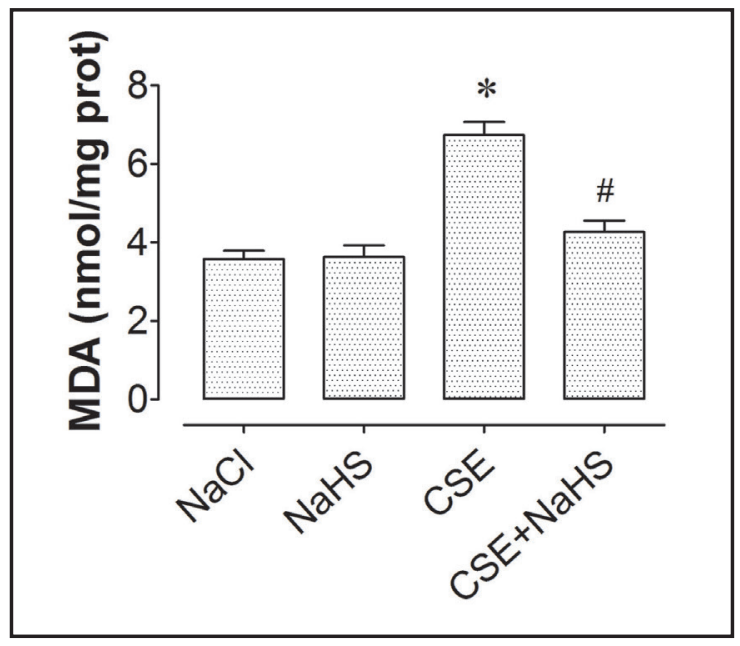

Fig. 2. NaHS alleviates CSE-induced lipid peroxidation in placentas. Comparisons of the contents of MDA in the $\mathrm{NaCl}$, NaHS, CSE and CSE+NaHS groups. ${ }^{*} \mathrm{P}<0.05$ vs. $\mathrm{NaCl}$ group; $\# \mathrm{P}<0.05$ vs. CSE group. $\mathrm{n}=6$ per group. 


\section{Cellular Physiology Cell Physiol Biochem 2018;48:1815-1828 \begin{tabular}{l|l|l} 
and Biochemistry & DOI: 10.1159/000492504 & $\begin{array}{l}\text { (c) } 2018 \text { The Author(s). Published by S. Karger AG, Basel } \\
\text { www.karger.com/cpb }\end{array}$
\end{tabular}

MDA content was markedly increased in the CSE group when compared with the $\mathrm{NaCl}$ group $(P<0.05)$. With NaHS treatment, however, the MDA content was significantly decreased in the $\mathrm{CSE}+\mathrm{NaHS}$ group compared with the CSE group $(P<0.05)$. In addition, the MDA contents did not vary significantly in the NaHS group compared with the $\mathrm{NaCl}$ group $(P>0.05)$. Taken together, these results indicate that NaHS application could alleviate placental oxidative damage induced by CSE in rats.

NaHS ameliorates placental redox imbalance caused by CSE

To investigate the effects of CSE and $\mathrm{H}_{2} \mathrm{~S}$ on redox status in placentas of our model, three sets of experiments were performed. First, the ROS was detected by using ROS Fluorescent Probe-CellROX in placentas (Fig. 3A). As shown in Fig. 3B, the mean fluorescence intensity of CellROX in the CSE group was strikingly increased compared with that in the $\mathrm{NaCl}$ group $(P<0.05)$, whereas the increased fluorescence intensity due to CSE was lowered with NaHS treatment in the CSE+NaHS group $(P<0.05)$; and there was no significant difference in levels of fluorescence intensity between the $\mathrm{NaHS}$ and $\mathrm{NaCl}$ groups $(P>0.05)$.

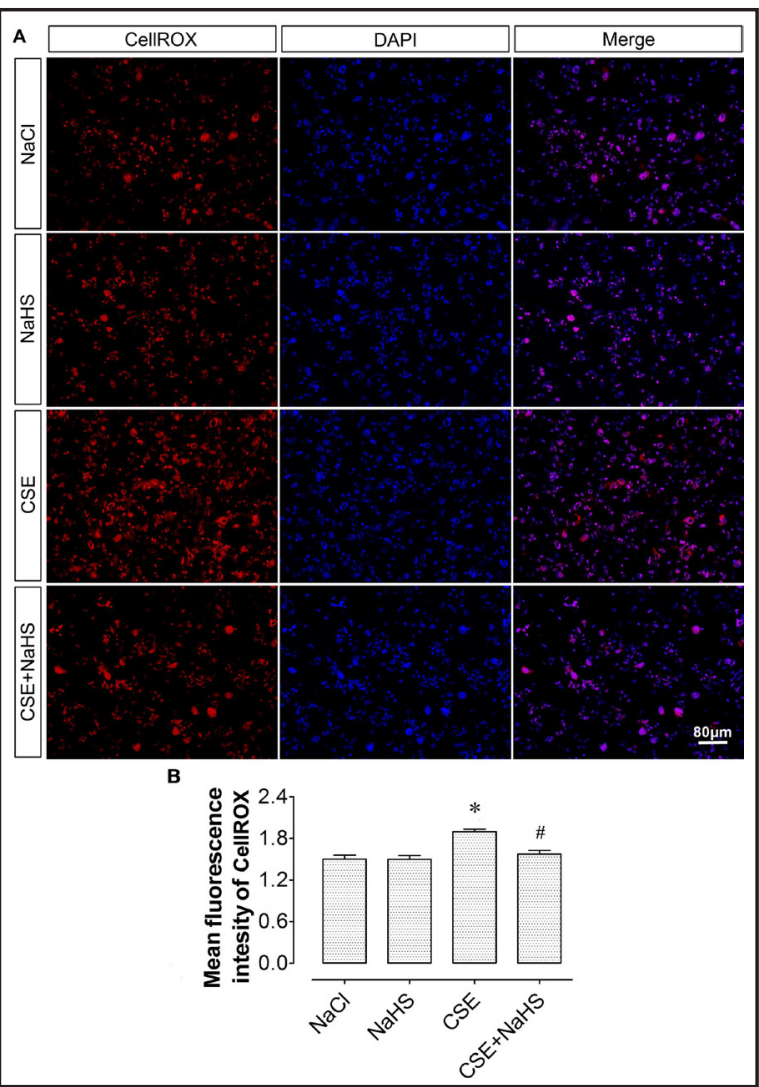

Fig. 3. NaHS inhibits ROS production induced by CSE in placentas. (A) Representative fluorescent images of placentas stained with CellROX in the $\mathrm{NaCl}$, NaHS, CSE and CSE+NaHS groups, respectively. (B) Comparisons of the mean fluorescence intensity of CellROX in the $\mathrm{NaCl}$, NaHS, CSE and CSE+NaHS groups. ${ }^{*} \mathrm{P}<0.05$ vs. $\mathrm{NaCl}$ group; $\# \mathrm{P}<0.05$ vs. CSE group. $\mathrm{n}=6$ per group.

Second, we probed the levels of total antioxidant activity (T-AOC), GSH, oxidized glutathione (GSSG) and GSH/GSSG ratio in placentas. As illustrated in Fig. 4A, the level of T-AOC was significantly lower in the CSE group compared with that in the $\mathrm{NaCl}$ group $(P<0.05)$. With administration of $\mathrm{NaHS}$, however, the T-AOC level was strikingly increased in the CSE+NaHS group compared with that in the CSE group $(P<0.05)$. There was no significant difference between the $\mathrm{NaHS}$ and $\mathrm{NaCl}$ groups in terms of T-AOC levels $(P>0.05)$. As shown in Fig. 4B-D, in the CSE group, the GSH content was decreased, the GSSG content was increased, and then the ratio of GSH/GSSG was significantly decreased, compared with the $\mathrm{NaCl}$ group $(P<0.05)$; in contrast to the CSE group, these effects were obviously reversed with NaHS treatment in the CSE+NaHS group $(P<0.05)$. No significant difference was found in GSH and GSSG contents as well as the GSH/GSSG ratio between the $\mathrm{NaHS}$ and $\mathrm{NaCl}$ groups $(P>0.05)$.

Third, we analyzed the anti-oxidative enzymes activities and expressions in placental homogenates. As shown in Fig. 4E-F, the activities of copper/zinc SOD (SOD1) and manganese SOD (SOD2) in the CSE group were significantly lower than those in the NaCl group $(P<0.05)$. However, SOD1 and SOD2 activities were restored by NaHS administration in the CSE+NaHS group compared to the CSE group $(P<0.05)$. There were not significant differences in activities of SOD1 and SOD2 between the $\mathrm{NaCl}$ and NaHS groups $(P>0.05)$. In contrast to the $\mathrm{NaCl}$ group, the CAT activity in the CSE group was significantly decreased $(P<0.05)$, whereas the reduced CAT activity was normalized with NaHS treatment in the CSE+NaHS group $(P<0.05)$. 


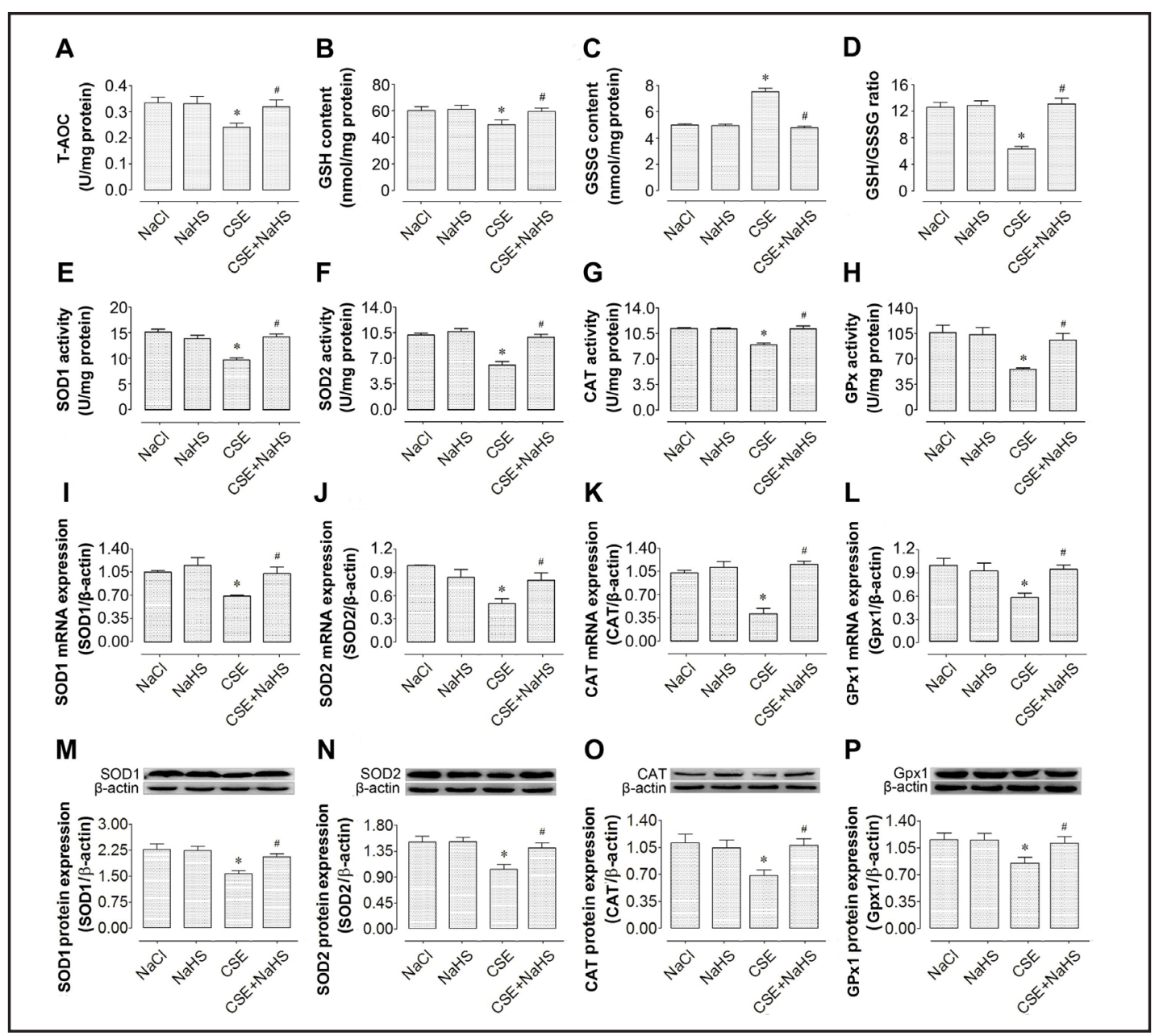

Fig. 4. NaHS alleviates placental redox imbalance caused by CSE. (A) Comparisons of the levels of T-AOC in the $\mathrm{NaCl}$, NaHS, CSE and CSE+NaHS groups. (B-D) Comparisons of the contents of GSH, GSSG and GSH/ GSSG ratio in placental homogenates from the NaCl, NaHS, CSE and CSE+NaHS groups, respectively. (E-H) Comparisons of the activities of SOD1, SOD2, CAT and total GPx in placental homogenates from the $\mathrm{NaCl}$, NaHS, CSE and CSE+NaHS groups. (I-L) Comparisons of the mRNA expression levels of Sod1, Sod2, Cat and GPx1 in placentas from the NaCl, NaHS, CSE and CSE+NaHS groups. (M-P) Representative immunoblots (upper) and densitometric analysis (lower), respectively, of SOD1, SOD2, CAT and GPx1 protein expressions in the $\mathrm{NaCl}$, NaHS, CSE and CSE+NaHS groups, respectively. ${ }^{*} \mathrm{P}<0.05$ vs. $\mathrm{NaCl}$ group; $\# \mathrm{P}<0.05$ vs. CSE group. $\mathrm{n}=6$ per group.

Meanwhile, CAT activities did not differ significantly between the $\mathrm{NaCl}$ and NaHS groups $(P>0.05)$ (Fig. 4G). Similarly, the activity of total GPx was also significantly decreased in the CSE group compared to the $\mathrm{NaCl}$ group $(P<0.05)$. However, the GPx activity was elevated with NaHS treatment in the CSE+NaHS group $(P<0.05)$; and there was no significant difference in GPx activity between the NaHS and $\mathrm{NaCl}$ groups $(P>0.05)$ (Fig. $4 \mathrm{H})$. As displayed in Fig. 4I-L, the mRNA expression levels of Sod1, Sod2, Cat and GPx1 were significantly decreased in the CSE group when compared with the $\mathrm{NaCl}$ group $(P<0.05)$. However, the decreases in mRNA expressions of the anti-oxidative genes due to CSE were significantly enhanced with NaHS administration in the CSE+NaHS group $(P<0.05)$; and none of the mRNA in the NaHS group was significantly different from that in the $\mathrm{NaCl}$ group $(P>0.05)$. In line with mRNA expression, the protein levels of SOD1, SOD2, CAT and GPx1 (Fig. 4M-P) were also significantly decreased in the CSE group when compared to the NaCl group $(P<0.05)$, whereas the lowered protein levels due to CSE were normalized with NaHS application in the CSE+NaHS group

\section{KARGER}




\section{Cellular Physiology Cell Physiol Biochem 2018;48:1815-1828

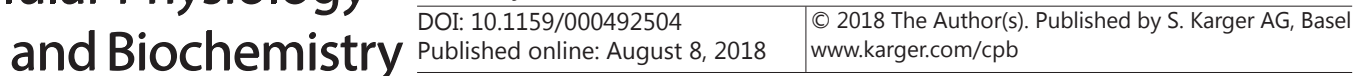

$(P<0.05)$. These results clearly indicate that $\mathrm{H}_{2} \mathrm{~S}$ could ameliorate placental redox status imbalance caused by CSE in rats.

\section{NaHS augments placental Nrf2} expression suppressed by CSE

To confirm whether the anti-oxidative effects of $\mathrm{H}_{2} \mathrm{~S}$ were associated with $\mathrm{Nrf2}$, a key regulator of endogenous antioxidants, we measured Nrf2 expression in placentas. As shown in Fig. 5A-B, abundant Nrf2 immunoreactivity was observed in placentas of the $\mathrm{NaCl}$ and $\mathrm{NaHS}$ groups. However, sparse immunoreactivity for Nrf2 was observed in the CSE group (Fig. 5C), which was normalized with NaHS treatment in the CSE+NaHS group (Fig. 5D). Quantitative analysis (Fig. 5E) revealed that the level of Nrf2 in the CSE group was significantly lower compared with that in the $\mathrm{NaCl}$ group $(P<0.05)$, whereas the decreased Nrf2 due to CSE was reversed with NaHS treatment $(P<0.05)$. There was no significant difference between the NaHS and $\mathrm{NaCl}$ groups in terms of Nrf2 levels $(P>0.05)$.

As shown in Fig. $5 \mathrm{~F}-\mathrm{G}$, the mRNA and protein expression levels of Nrf2 in the CSE group were also significantly decreased compared with those in the $\mathrm{NaCl}$ group $(P<0.05)$. However, in contrast to the CSE group, the decreases both in mRNA and protein expressions of $\mathrm{Nrf} 2$ were dramatically elevated with NaHS treatment in the CSE+NaHS group $(P<0.05)$. Additionally, there was no significant difference in Nrf2 expressions between the $\mathrm{NaHS}$ and $\mathrm{NaCl}$ groups $(P>0.05)$. Taken together, these results suggest that $\mathrm{H}_{2} \mathrm{~S}$ was a potent inducer for Nrf2 as well as Nrf2-

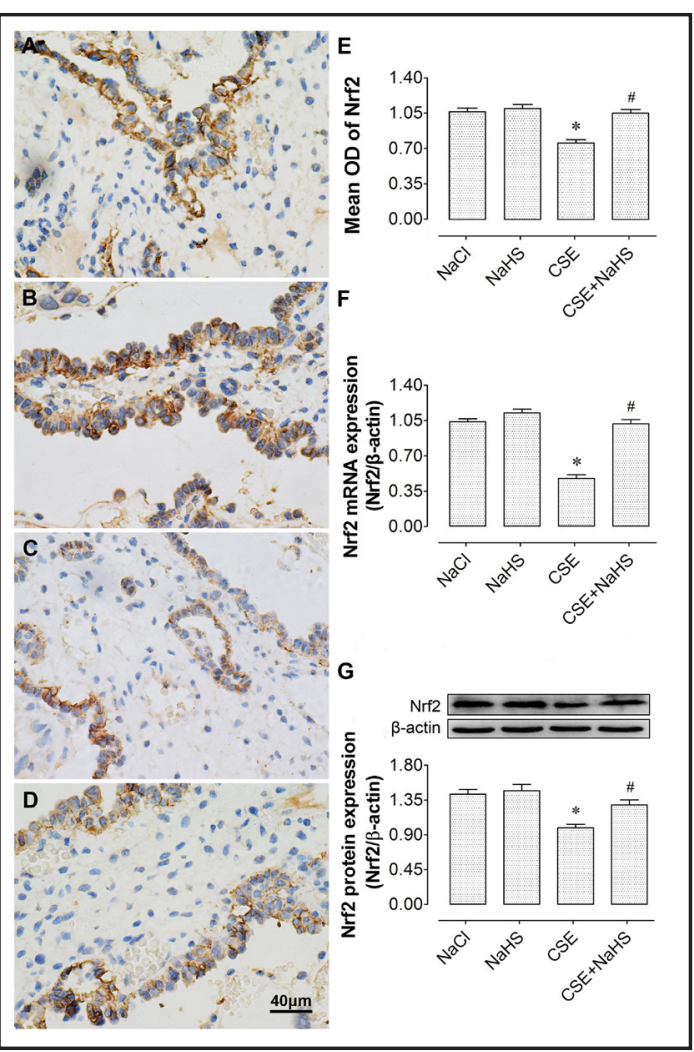

Fig. 5. NaHS augments Nrf2 expression suppressed by CSE in placentas. (A-D) Representative images for Nrf2 immunostaining in placentas of the $\mathrm{NaCl}$, NaHS, CSE and CSE+NaHS groups, respectively. (E) Comparisons of optical density (OD) of Nrf2 in the $\mathrm{NaCl}, \mathrm{NaHS}, \mathrm{CSE}$ and CSE+NaHS groups. (F) Comparisons of the mRNA expression levels of Nrf2 in placentas from the $\mathrm{NaCl}, \mathrm{NaHS}, \mathrm{CSE}$ and $\mathrm{CSE}+\mathrm{NaHS}$ groups. (G) Representative immunoblots (upper) and densitometric analysis (lower), respectively, of Nrf2 protein expressions in the $\mathrm{NaCl}, \mathrm{NaHS}, \mathrm{CSE}$ and CSE + NaHS groups. ${ }^{*} \mathrm{P}<0.05$ vs. $\mathrm{NaCl}$ group; $\# \mathrm{P}<0.05$ vs. CSE group. $n=6$ per group. regulated anti-oxidative genes expressions in response to CSE in rat placentas.

\section{Discussion}

The results presented in this study showed that $\mathrm{H}_{2} \mathrm{~S}$ donor NaHS could protect against CSE-induced placental oxidative damage in rats. Histological staining revealed that NaHS could alleviate placental DNA damage due to CSE. Meanwhile, NaHS markedly reduced CSEinduced lipid peroxidation in placentas. Further, NaHS effectively mitigated CSE-induced placental redox imbalance by suppressing ROS production, restoring T-AOC level, increasing GSH/GSSG ratio, and augmenting SOD1, SOD2, CAT and GPx activities and expressions. More notably, NaHS could also induce Nrf2 mRNA and protein expressions in CSE placentas. Thus, our findings suggest that $\mathrm{H}_{2} \mathrm{~S}$ could ameliorate CSE-induced placental damage, which might be associated with attenuation of redox imbalance via up-regulation of Nrf2 and the 


\section{Cellular Physiology Cell Physiol Biochem 2018;48:1815-1828 \\ \begin{tabular}{c|c|c|} 
DOI: 10.1159/000492504 & and Biochemistry \\
Published online: August 8, 2018 & $\begin{array}{l}\text { 2018 The Author(s). Published by S. Karger AG, Basel } \\
\text { www.karger.com/cpb }\end{array}$
\end{tabular}}

Zhao et al.: Hydrogen Sulfide and Placental Oxidative Damage

expression of Nrf2-mediated anti-oxidative gene targets in placentas.

Cigarette smoke contains scores of toxins which have detrimental effects on placentation, affecting both the vascular and trophoblast compartments [6]. Previously, a clinical study revealed that the levels of $8-0 \mathrm{HdG}$, a reliable biomarker of oxidative DNA damage, was significantly increased in the bronchial epithelial cells of smoking patients [52]. In our investigation, with the CSE rat model, we observed that the 8-OHdG was markedly increased in the CSE rat placentas, which was in line with previous research wherein a high level of 8-OHdG was noticed in the placentas of women smokers [53]. Interestingly, in the present study, the increased 8-OHdG in the placentas of rats exposed to cigarette smoke was distinctly reduced with NaHS treatment. Consistent with our findings, studies revealed that the levels of 8-OHdG and MDA were decreased upon NaHS application in in vivo model of cigarette smoke-induced emphysema [54] and in vitro model of hypoxia/reoxygenation-induced cardiomyocytes injury [55]. Moreover, our previous studies also proved that treatment with NaHS could antagonize hypoxia-induced increase in MDA content in medulla oblongata of adult rats [43] and in medullary slices of neonatal rats [56]. The amounts of MDA often reflect the degree of lipid peroxidation in tissues and indirectly reflect the degree of cell damage. We herein measured the MDA content and found a sharp rise of MDA content in the placentas of rats exposed to cigarette smoke. However, as expected, our results showed that the accumulation of MDA due to CSE in placentas was reduced with NaHS application, which implicates a protective role of $\mathrm{H}_{2} \mathrm{~S}$ against CSE-induced placental oxidative damage.

Excess production of ROS or inadequate anti-oxidative capacity may alter the cellular redox balance resulting in a phenomenon known as oxidative stress [57]. ROS emitted by cigarette smoke and produced from the inflammatory cells and the structural cells lead to direct or indirect damage of nucleic acids, proteins, and lipids, and are involved in the pathogenesis of various diseases $[54,58,59]$. Consistent with this notion, by using the CSE rat model, we found that the ROS level in the CSE placentas was markedly increased, however, the excess ROS were noticeably cleared with NaHS application. In line with our findings, a recent study reported that chronic CSE enhanced myocardial ROS levels and resulted in left ventricular remodeling and dysfunction, whereas $\mathrm{H}_{2} \mathrm{~S}$ remarkably ameliorated these adverse events via attenuation of the oxidative stress in rats [60]. Besides the dramatic increase in ROS, we also observed a distinct decrease of GSH/GSSG ratio in the placentas of CSE rats. In mammalian cells, GSH is considered as a major antioxidant that scavenges free radicals and other reactive nitrogen species directly or indirectly through enzymatic reaction [24]. When oxidative stress occurs, GSH will become GSSG during the process of binding free radicals, and the GSH/GSSG ratio rapidly decreases [61]. Also, we found in this study that the T-AOC, an indicator of total antioxidant status reflecting the degree of oxidative damage in cells [62], was markedly decreased in CSE rat placentas, whereas the decreased T-AOC due to CSE was antagonized with NaHS administration.

In mammals, there are three distinctive SODs, SOD1, SOD2 and the extracellular SOD (SOD3) [63]. SOD1 is the major intracellular form of SOD, accounting for $\sim 80 \%$ total SOD proteins. SOD2 is exclusively localized in the mitochondrial matrix, whereas SOD3 is the secreted form that is mainly associated with the extracellular matrix of different tissues [63]. Together, these SOD enzymes scavenge superoxide anion into molecular oxygen and hydrogen peroxide, then CAT and GPx reduce hydrogen peroxide, thus preventing production of highly toxic hydroxyl radical [64]. Growing evidence indicates that cigarette smoking or CSE significantly decrease the activities of anti-oxidative enzymes both in vitro and in vivo researches $[65,66]$. In the present study, our results displayed a significant reduction in activities of SOD1, SOD2, CAT and total GPx in CSE rat placentas, however, the decreased activities of the anti-oxidative enzymes were improved with NaHS application. In line with elevation of anti-oxidative enzymes activities, we also observed that NaHS application dramatically increased anti-oxidative genes mRNA and protein expression levels in CSE rat placentas. Accumulating evidence indicates that $\mathrm{H}_{2} \mathrm{~S}$ can selectively scavenge hydroxyl radicals and peroxynitrite, and is involved in modulating anti-oxidative genes expression under oxidative stress conditions [67]. For instance, a previous study revealed 
that administration of NaHS could effectively ameliorate CSE-induced pulmonary fibrosis via attenuation of oxidative stress in rats [22]. Consistent with these findings, we found in this study that the mRNA and protein expressions of anti-oxidants in the CSE rat placentas were up-regulated with NaHS treatment. Taken together, these results unequivocally demonstrate that CSE during pregnancy can give rise to placental redox imbalance, however $\mathrm{H}_{2} \mathrm{~S}$ is capable of ameliorating the redox imbalance, which might be due to its potential to reduce ROS production, increase GSH/GSSG ratio and augment anti-oxidative enzymes activities and expressions in rats.

To explore the underlying mechanism of anti-oxidative effects for $\mathrm{H}_{2} \mathrm{~S}$, we further investigated the effects of NaHS on Nrf2 expression in rat placentas. Although emerging evidence has shown that Nrf2 is one of the major cellular defense lines against oxidative stress, and its influences on anti-oxidative genes have been widely established [68], the effects of $\mathrm{H}_{2} \mathrm{~S}$ on Nrf2 pathway have never been described in the placenta. Several studies have suggested that Nrf2 plays a protective role in pulmonary diseases incurred by cigarette smoking including acute lung injury [26], chronic obstructive pulmonary disease [69] and asthma [70]. Clinically, Nrf2 protein expression was found to be significantly decreased in both lung tissues and alveolar macrophages from smokers [71]. In animals, activation of Nrf2 has been found to attenuate airway inflammation and emphysema incurred by CSE in mice [54]. In the current study, we found that the levels of Nrf2 mRNA and protein were distinctly lowered in CSE rat placentas, however, the decrease in Nrf2 was normalized with $\mathrm{NaHS}$ treatment. It suggests that $\mathrm{H}_{2} \mathrm{~S}$ may, at least in part, augment Nrf2 expression that is suppressed by CSE in rats, and consequently initiate Nrf2-mediated anti-oxidative genes including Sod1, Sod2, CAT and GPx1 expressions in placentas. Nevertheless, whether CSE and $\mathrm{H}_{2} \mathrm{~S}$ alter the levels of nuclear Nrf2 and some other downstream antioxidants such as heme oxygenase- 1 needs to be further investigated.

In conclusion, the present study demonstrates that $\mathrm{H}_{2} \mathrm{~S}$ can protect against CSE-induced placental oxidative damage in rats, perhaps through $\mathrm{H}_{2} \mathrm{~S}$ free radical scavenging activities, and by alleviating placental redox imbalance via regulation of Nrf2 pathway. Although the molecular mechanisms of $\mathrm{H}_{2} \mathrm{~S}$ actions remain unclear, our findings provide new insight into the biological effects of $\mathrm{H}_{2} \mathrm{~S}$ and suggest a potential therapeutic approach for placental injury caused by CSE.

\section{Acknowledgements}

This work was supported by grants from the National Natural Science Foundation of China (Nos. 31471096 and 31271233).

\section{Disclosure Statement}

No conflict of interests exists.

\section{References}

1 Cesar-Neto JB, Duarte PM, de Oliveira MC, Casati MZ, Tambeli CH, Parada CA, Sallum EA, Nociti FH, Jr.: Smoking modulates interferon-gamma expression in the gingival tissue of patients with chronic periodontitis. Eur J Oral Sci 2006;114:403-408.

- Inoue T, Oku K, Kimoto K, Takao M, Nomoto J, Handa K, Kono S, Arakawa K: Relationship of cigarette smoking to the severity of coronary and thoracic aortic atherosclerosis. Cardiology 1995;86:374-379.

- Almeida OP, Garrido GJ, Lautenschlager NT, Hulse GK, Jamrozik K, Flicker L: Smoking is associated with reduced cortical regional gray matter density in brain regions associated with incipient Alzheimer disease. Am J Geriatr Psychiatry 2008;16:92-98. 


\section{Cellular Physiology Cell Physiol Biochem 2018;48:1815-1828

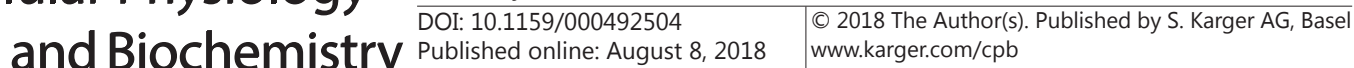

4 Cosio MG, Hale KA, Niewoehner DE: Morphologic and morphometric effects of prolonged cigarette smoking on the small airways. Am Rev Respir Dis 1980;122:265-221.

5 Einarson A, Riordan S: Smoking in pregnancy and lactation: a review of risks and cessation strategies. Eur J Clin Pharmacol 2009;65:325-330.

6 Jauniaux E, Burton GJ: Morphological and biological effects of maternal exposure to tobacco smoke on the feto-placental unit. Early Hum Dev 2007;83:699-706.

7 Rogers JM: Tobacco and pregnancy. Reprod Toxicol 2009;28:152-160.

$>8$ Demir R, Demir AY, Yinanc M: Structural changes in placental barrier of smoking mother. A quantitative and ultrastructural study. Pathol Res Pract 1994;190:656-667.

9 Asmussen I: Ultrastructure of the human placenta at term. Observations on placentas from newborn children of smoking and non-smoking mothers. Acta Obstet Gynecol Scand 1977;56:119-126.

$\checkmark 10$ Albuquerque CA, Smith KR, Johnson C, Chao R, Harding R: Influence of maternal tobacco smoking during pregnancy on uterine, umbilical and fetal cerebral artery blood flows. Early Hum Dev 2004;80:31-42.

11 Piasek M, Blanusa M, Kostial K, Laskey JW: Placental cadmium and progesterone concentrations in cigarette smokers. Reprod Toxicol 2001;15:673-681.

12 Zhu BT, Cai MX, Spink DC, Hussain MM, Busch CM, Ranzini AC, Lai YL, Lambert GH, Thomas PE, Conney AH: Stimulatory effect of cigarette smoking on the 15 alpha-hydroxylation of estradiol by human term placenta. Clin Pharmacol Ther 2002;71:311-324.

13 Pastrakuljic A, Derewlany LO, Koren G: Maternal cocaine use and cigarette smoking in pregnancy in relation to amino acid transport and fetal growth. Placenta 1999;20:499-512.

-14 Collier AC, Tingle MD, Paxton JW, Mitchell MD, Keelan JA: Metabolizing enzyme localization and activities in the first trimester human placenta: the effect of maternal and gestational age, smoking and alcohol consumption. Hum Reprod 2002;17:2564-2572.

-15 Aliyu MH, Lynch O, Wilson RE, Alio AP, Kristensen S, Marty PJ, Whiteman VE, Salihu HM: Association between tobacco use in pregnancy and placenta-associated syndromes: a population-based study. Arch Gynecol Obstet 2011;283:729-734.

-16 Salihu HM, Wilson RE: Epidemiology of prenatal smoking and perinatal outcomes. Early Hum Dev 2007;83:713-720.

17 Wagijo MA, Sheikh A, Duijts L, Been JV: Reducing tobacco smoking and smoke exposure to prevent preterm birth and its complications. Paediatr Respir Rev 2017;22:3-10.

18 Burns DM: Cigarettes and cigarette smoking. Clin Chest Med 1991;12:631-642.

19 van der Toorn M, Rezayat D, Kauffman HF, Bakker SJ, Gans RO, Koeter GH, Choi AM, van Oosterhout AJ, Slebos DJ: Lipid-soluble components in cigarette smoke induce mitochondrial production of reactive oxygen species in lung epithelial cells. Am J Physiol Lung Cell Mol Physiol 2009;297:L109-114.

20 Ma Q: Transcriptional responses to oxidative stress: pathological and toxicological implications. Pharmacol Ther 2010;125:376-393.

-21 Al Hariri M, Zibara K, Farhat W, Hashem Y, Soudani N, Al Ibrahim F, Hamade E, Zeidan A, Husari A, Kobeissy F: Cigarette Smoking-Induced Cardiac Hypertrophy, Vascular Inflammation and Injury Are Attenuated by Antioxidant Supplementation in an Animal Model. Front Pharmacol 2016;7:397.

-22 Zhou X, An G, Chen J: Inhibitory effects of hydrogen sulphide on pulmonary fibrosis in smoking rats via attenuation of oxidative stress and inflammation. J Cell Mol Med 2014;18:1098-1103.

23 Yang G, Li Y, Wu W, Liu B, Ni L, Wang Z, Miao S, Wang L, Liu C: Anti-oxidant effect of heme oxygenase-1 on cigarette smoke-induced vascular injury. Mol Med Rep 2015;12:2481-2486.

24 Aquilano K, Baldelli S, Ciriolo MR: Glutathione: new roles in redox signaling for an old antioxidant. Front Pharmacol 2014;5:196.

25 Yang G, Zhao K, Ju Y, Mani S, Cao Q, Puukila S, Khaper N, Wu L, Wang R: Hydrogen sulfide protects against cellular senescence via S-sulfhydration of Keap1 and activation of Nrf2. Antioxid Redox Signal 2013;18:1906-1919.

-26 Yamada K, Asai K, Nagayasu F, Sato K, Ijiri N, Yoshii N, Imahashi Y, Watanabe T, Tochino Y, Kanazawa H, Hirata K: Impaired nuclear factor erythroid 2-related factor 2 expression increases apoptosis of airway epithelial cells in patients with chronic obstructive pulmonary disease due to cigarette smoking. BMC Pulm Med 2016;16:27.

27 Shih AY, Li P, Murphy TH: A small-molecule-inducible Nrf2-mediated antioxidant response provides effective prophylaxis against cerebral ischemia in vivo. J Neurosci 2005;25:10321-10335. 


\section{Cellular Physiology Cell Physiol Biochem 2018;48:1815-1828 \begin{tabular}{l|l} 
and Biochemistry DOI: 10.1159/000492504 & $\begin{array}{l}\text { (c) } 2018 \text { The Author(s). Published by S. Karger AG, Basel } \\
\text { www.karger.com/cpb }\end{array}$
\end{tabular}

28 Shah ZA, Li RC, Thimmulappa RK, Kensler TW, Yamamoto M, Biswal S, Dore S: Role of reactive oxygen species in modulation of Nrf2 following ischemic reperfusion injury. Neuroscience 2007;147:53-59.

29 Rangasamy T, Cho CY, Thimmulappa RK, Zhen L, Srisuma SS, Kensler TW, Yamamoto M, Petrache I, Tuder RM, Biswal S: Genetic ablation of Nrf2 enhances susceptibility to cigarette smoke-induced emphysema in mice. J Clin Invest 2004;114:1248-1259.

-30 Iizuka T, Ishii Y, Itoh K, Kiwamoto T, Kimura T, Matsuno Y, Morishima Y, Hegab AE, Homma S, Nomura A, Sakamoto T, Shimura M, Yoshida A, Yamamoto M, Sekizawa K: Nrf2-deficient mice are highly susceptible to cigarette smoke-induced emphysema. Genes Cells 2005;10:1113-1125.

-31 Sussan TE, Rangasamy T, Blake DJ, Malhotra D, El-Haddad H, Bedja D, Yates MS, Kombairaju P, Yamamoto M, Liby KT, Sporn MB, Gabrielson KL, Champion HC, Tuder RM, Kensler TW, Biswal S: Targeting Nrf2 with the triterpenoid CDDO-imidazolide attenuates cigarette smoke-induced emphysema and cardiac dysfunction in mice. Proc Natl Acad Sci U S A 2009;106:250-255.

-32 Srivastava S, Alfieri A, Siow RC, Mann GE, Fraser PA: Temporal and spatial distribution of Nrf2 in rat brain following stroke: quantification of nuclear to cytoplasmic Nrf2 content using a novel immunohistochemical technique. J Physiol 2013;591:3525-3538.

-33 Zhou S, Sun W, Zhang Z, Zheng Y: The role of Nrf2-mediated pathway in cardiac remodeling and heart failure. Oxid Med Cell Longev 2014;2014:260429.

34 Kawata K, Kobayashi Y, Souda K, Kawamura K, Sumiyoshi S, Takahashi Y, Noritake H, Watanabe S, Suehiro T, Nakamura H: Enhanced hepatic Nrf2 activation after ursodeoxycholic acid treatment in patients with primary biliary cirrhosis. Antioxid Redox Signal 2010;13:259-268.

35 Kimura H: Physiological role of hydrogen sulfide and polysulfide in the central nervous system. Neurochem Int 2013;63:492-497.

-36 Wang R: The gasotransmitter role of hydrogen sulfide. Antioxid Redox Signal 2003;5:493-501.

-37 Li H, Wang Y, Wei C, Bai S, Zhao Y, Li H, Wu B, Wang R, Wu L, Xu C: Mediation of exogenous hydrogen sulfide in recovery of ischemic post-conditioning-induced cardioprotection via down-regulating oxidative stress and up-regulating PI3K/Akt/GSK-3beta pathway in isolated aging rat hearts. Cell Biosci 2015;5:11.

38 Wang D, Ma Y, Li Z, Kang K, Sun X, Pan S, Wang J, Pan H, Liu L, Liang D, Jiang H: The role of AKT1 and autophagy in the protective effect of hydrogen sulphide against hepatic ischemia/reperfusion injury in mice. Autophagy 2012;8:954-962.

-39 Florian B, Vintilescu R, Balseanu AT, Buga AM, Grisk O, Walker LC, Kessler C, Popa-Wagner A: Long-term hypothermia reduces infarct volume in aged rats after focal ischemia. Neurosci Lett 2008;438:180-185.

40 Han ZH, Jiang YI, Duan YY, Wang XY, Huang Y, Fang TZ: Protective effects of hydrogen sulfide inhalation on oxidative stress in rats with cotton smoke inhalation-induced lung injury. Exp Ther Med 2015;10:164-168.

41 Zhou X, An G, Chen J: Hydrogen sulfide improves left ventricular function in smoking rats via regulation of apoptosis and autophagy. Apoptosis 2014;19:998-1005.

42 Nie LH, Hu Y, Yan X, Li MQ Chen L, Li H, Li XK, Zhou H, Zheng Y: The anti-apoptotic effect of hydrogen sulfide attenuates injuries to the medullary respiratory centers of neonatal rats subjected to in utero cigarette smoke exposure. Respiratory Physiology \& Neurobiology 2013;188:29-38.

43 Li H, Chen L, Hou X, Zhou H, Zheng Y: Hydrogen sulfide attenuates hypoxia-induced respiratory suppression in anesthetized adult rats. Respir Physiol Neurobiol 2016;220:1-9.

-44 Zhang S, Lei F, Zhao F, Yan X, Wang W, Zheng Y: Hydrogen sulfide ameliorates prenatal cigarette smoke exposure-induced impairment of respiratory responses to hypercapnia in neonatal rats. Respir Physiol Neurobiol 2017;243:1-6.

45 Klebanoff MA, Levine RJ, Clemens JD, DerSimonian R, Wilkins DG: Serum cotinine concentration and selfreported smoking during pregnancy. American Journal of Epidemiology 1998;148:259-262.

-46 Vasankari T, Jousilahti P, Knekt P, Marniemi J, Heistaro S, Lppo K, Heliovaara M: Serum cotinine predicts bronchial obstruction regardless of self-reported smoking history. Scand J Public Health 2011;39:547-552.

47 Lu J, Wu DM, Zheng ZH, Zheng YL, Hu B, Zhang ZF: Troxerutin protects against high cholesterol-induced cognitive deficits in mice. Brain 2011;134:783-797.

48 Xu X, Lv H, Xia Z, Fan R, Zhang C, Wang Y, Wang D: Rhein exhibits antioxidative effects similar to Rhubarb in a rat model of traumatic brain injury. BMC Complement Altern Med 2017;17:140.

49 Stangenberg S, Nguyen LT, Chen H, Al-Odat I, Killingsworth MC, Gosnell ME, Anwer AG, Goldys EM, Pollock CA, Saad S: Oxidative stress, mitochondrial perturbations and fetal programming of renal disease induced by maternal smoking. Int J Biochem Cell Biol 2015;64:81-90. 


\section{Cellular Physiology Cell Physiol Biochem 2018;48:1815-1828 \begin{tabular}{ll|l} 
DOI: 10.1159/000492504 & and Biochemistry 2018 The Author(s). Published by S. Karger AG, Basel \\
wwww.karger.com/cpb
\end{tabular}

-50 Wang X, Wang Q, Guo W, Zhu YZ: Hydrogen sulfide attenuates cardiac dysfunction in a rat model of heart failure: a mechanism through cardiac mitochondrial protection. Biosci Rep 2011;31:87-98.

51 Liu S, Zhou F, Shen Y, Zhang Y, Yin H, Zeng Y, Liu J, Yan Z, Liu X: Fluid shear stress induces epithelialmesenchymal transition (EMT) in Hep-2 cells. Oncotarget 2016;7:32876-32892.

-52 Cao C, Lai T, Li M, Zhou H, Lv D, Deng Z, Ying S, Chen Z, Li W, Shen H: Smoking-promoted oxidative DNA damage response is highly correlated to lung carcinogenesis. Oncotarget 2016;7:18919-18926.

53 Sbrana E, Suter MA, Abramovici AR, Hawkins HK, Moss JE, Patterson L, Shope C, Aagaard-Tillery K: Maternal tobacco use is associated with increased markers of oxidative stress in the placenta. Am J Obstet Gynecol 2011;205:246 e241-247.

54 Han W, Dong Z, Dimitropoulou C, Su Y: Hydrogen sulfide ameliorates tobacco smoke-induced oxidative stress and emphysema in mice. Antioxid Redox Signal 2011;15:2121-2134.

55 Li L, Li M, Li Y, Sun W, Wang Y, Bai S, Li H, Wu B, Yang G, Wang R, Wu L, Li H, Xu C: Exogenous H2S contributes to recovery of ischemic post-conditioning-induced cardioprotection by decrease of ROS level via down-regulation of NF-kappaB and JAK2-STAT3 pathways in the aging cardiomyocytes. Cell Biosci 2016;6:26.

56 Pan JG, Hu HY, Zhang J, Zhou H, Chen L, Tang YH, Zheng Y: Protective effect of hydrogen sulfide on hypoxic respiratory suppression in medullary slice of neonatal rats. Respir Physiol Neurobiol 2010;171:181-186.

57 Marcellin L, Santulli P, Chouzenoux S, Cerles O, Nicco C, Dousset B, Pallardy M, Kerdine-Romer S, Just PA, Chapron C, Batteux F: Alteration of Nrf2 and Glutamate Cysteine Ligase expression contribute to lesions growth and fibrogenesis in ectopic endometriosis. Free Radic Biol Med 2017;110:1-10.

58 Mainali P, Pant S, Rodriguez AP, Deshmukh A, Mehta JL: Tobacco and cardiovascular health. Cardiovasc Toxicol 2015;15:107-116.

59 Warren GW, Sobus S, Gritz ER: The biological and clinical effects of smoking by patients with cancer and strategies to implement evidence-based tobacco cessation support. Lancet Oncol 2014;15:e568-580.

-60 Zhou X, Zhao L, Mao J, Huang J, Chen J: Antioxidant effects of hydrogen sulfide on left ventricular remodeling in smoking rats are mediated via PI3K/Akt-dependent activation of Nrf2. Toxicol Sci 2015;144:197-203.

61 Palace V, Kumar D, Hill MF, Khaper N, Singal PK: Regional differences in non-enzymatic antioxidants in the heart under control and oxidative stress conditions. J Mol Cell Cardiol 1999;31:193-202.

62 Gao Z, Zhang C, Tian W, Liu K, Hou R, Yue C, Wu Y, Wang D, Liu J, Hu Y, Yang Y: The antioxidative and hepatoprotective effects comparison of Chinese angelica polysaccharide(CAP)and selenizing CAP (sCAP) in CCl4 induced hepatic injury mice. Int J Biol Macromol 2017;97:46-54.

63 Che M, Wang R, Li X, Wang HY, Zheng XF: Expanding roles of superoxide dismutases in cell regulation and cancer. Drug Discov Today 2016;21:143-149.

64 Fukai T, Ushio-Fukai M: Superoxide dismutases: role in redox signaling, vascular function, and diseases. Antioxid Redox Signal 2011;15:1583-1606.

65 Nguyen LT, Stangenberg S, Chen H, Al-Odat I, Chan YL, Gosnell ME, Anwer AG, Goldys EM, Pollock CA, Saad S: L-Carnitine reverses maternal cigarette smoke exposure-induced renal oxidative stress and mitochondrial dysfunction in mouse offspring. Am J Physiol Renal Physiol 2015;308:F689-696.

66 Rababa'h AM, Sultan BB, Alzoubi KH, Khabour OF, Ababneh MA: Exposure to waterpipe smoke induces renal functional and oxidative biomarkers variations in mice. Inhal Toxicol 2016;28:508-513.

67 Wang R: Physiological implications of hydrogen sulfide: a whiff exploration that blossomed. Physiol Rev 2012;92:791-896.

68 Prasad S, Sajja RK, Kaisar MA, Park JH, Villalba H, Liles T, Abbruscato T, Cucullo L: Role of Nrf2 and protective effects of Metformin against tobacco smoke-induced cerebrovascular toxicity. Redox Biol 2017;12:58-69.

69 Boutten A, Goven D, Artaud-Macari E, Boczkowski J, Bonay M: NRF2 targeting: a promising therapeutic strategy in chronic obstructive pulmonary disease. Trends Mol Med 2011;17:363-371.

-70 Rangasamy T, Guo J, Mitzner WA, Roman J, Singh A, Fryer AD, Yamamoto M, Kensler TW, Tuder RM, Georas SN, Biswal S: Disruption of Nrf2 enhances susceptibility to severe airway inflammation and asthma in mice. J Exp Med 2005;202:47-59.

71 Goven D, Boutten A, Lecon-Malas V, Marchal-Somme J, Amara N, Crestani B, Fournier M, Leseche G, Soler P, Boczkowski J, Bonay M: Altered Nrf2/Keap1-Bach1 equilibrium in pulmonary emphysema. Thorax 2008;63:916-924. 